\title{
Poverty challenges in education context: a case study of transformation of the mindset of a non-governmental organization
}

\author{
Abdul Talib Hashim ${ }^{1}$, , Rosma Osman ${ }^{1}$, Fairuz Syazwani Badioze-Zaman ${ }^{2}$ \\ ${ }^{1}$ Sultan Idris Education University (UPSI), Tanjung Malim, Malaysia \\ ${ }^{2}$ Yayasan Bina Upaya Darul Ridzuan, Ipoh, Malaysia
}

\section{A R T I C L E I N F O}

\section{Article history:}

Received 2 September 2016

Received in revised form

25 October 2016

Accepted 4 November 2016

\section{Keywords:}

Poverty

Education

Non-governmental organizations

Corporate social responsibility

\begin{abstract}
A B S T R A C T
This study attempts to explore poverty challenges in education context faced by a non-governmental organization (NGO) responsible in carrying out its corporate social responsibility to the community. Research questions of this study are to explore the meaning of poverty based on the NGO definition; identify the efforts created for the community and the impact from those efforts. This study was carried out using case study. Respondents were selected through purposive sampling that involves only three respondents who works for the selected organization. The data collection techniques used in this study is semi-structured interviews, document analysis, observation and reflection notes. The study found that the cause of poverty is closely linked to economic factors and mindset poverty. With regards to efforts carried out by the NGO, the study found that the impact on the target group is quite satisfactory. Efforts undertaken by the organization has helped a number of poor students from the trap and vicious circle of poverty. Continuous efforts by NGO in this study can serve as a guide for future studies in addressing mindset poverty issue in this country.
\end{abstract}

(C) 2016 The Authors. Published by IASE. This is an open access article under the CC BY-NC-ND license (http://creativecommons.org/licenses/by-nc-nd/4.0/).

\section{Introduction}

Since the country's independence on August 31, 1957, the Malaysian government has initiated various efforts to ensure that all citizens throughout the country have equal rights in terms of standard of living, education, health, welfare and many others. Regardless of their differences whether they live in urban or rural areas, the policies enacted by the government has always been concern for the welfare of its citizens. However, there are still problems faced by these people such as poverty, education, health etc.

To ensure that all policies are implemented as planned, the government has collaborated with relevant implementing agencies to assist them in their objectives and goals for community development (Amran and Devi, 2008). The agencies appointed play an important role in ensuring that the plans are comprehensive addressing all aspects namely budget, political factors, economic, social, people etc. In addition, the government also

\footnotetext{
* Corresponding Author.

Email Address: abdul.talib@fppm.upsi.edu.my (A. T. Hashim)

https://doi.org/10.21833/ijaas.2016.11.008

2313-626X/C 2016 The Authors. Published by IASE.

This is an open access article under the CC BY-NC-ND license (http://creativecommons.org/licenses/by-nc-nd/4.0/)
}

collaborates with corporate companies in addressing the various aspects mentioned (Mustaruddin et al., 2010). This collaboration is termed Corporate Social Responsibility (CSR). CSR is a concept that encourages every company or organization or firm to give their support and assistance on welfare of the general public (Chapple and Moon, 2005; Vilanova et al., 2009). At the very least, CSR ensures that the welfare of society are well taken care of and not shouldered by the government alone (Mustaruddin, et al., 2010; Abdifatah, 2013).

In order to help people out of poverty, education is a platform for them to get a better living especially in the current economic situation. What is the function of education to individuals, communities and countries? According to Amir (2009), education contributes to the sustainability of society and therefore it is necessary to support the overall goals of the community. The existence of school and its system are due to insistence on the need to provide labor and division of labor in society (Drucker, 1994; Hussein, 2012). However, as the country progresses, development becomes dynamic and modern, education becomes more important than before that it does not only serves to provide labor but also contributes to diversity (Nisar, 2013). This education is not new in the public structure but it has long been obligated on every individual as stated the Quran: 
"O you who have believed, when you are told, "Space yourselves" in assemblies, then make space; Allah will make space for you. And when you are told, "Arise," then arise; Allah will raise those who have believed among you and those who were given knowledge, by degrees. And Allah is Acquainted with what you do" (Al-Mujadalah, 58:11).

In addition, the problem of poverty can be understood by understanding it's vicious. This scenario occurs due to the standard of living that begins from a poor family that is unable to provide educational needs to its family members, and thus become a tradition passed down to their children and grandchildren; The failure of parents to provide education to their children making it difficult for them to change the condition of their lives (Drucker, 1994; Hussein, 2012). The need for education is very important because it is a platform for people who want to change the condition of their lives and their families.

\section{Education and poverty}

Education has become one of the basic human needs. Nowadays, getting basic needs such as food, shelter and clothing require education to ensure better living condition. Without knowledge and education, most people could not live a better quality of life now. However, poverty is also seen as an obstacle for someone to get good education (Drucker, 1994; Hussein, 2012). Naschold (2012) stated that households are impeded by poverty on several factors, namely poverty, physical weakness, poor endurance, marginalized and powerless. Another study by Barrett and Carter (2013) also added some factors for poverty trap namely poor health, lack of education and illiteracy, lack of interaction with the educated, lack of involvement in public decision-making and limited acceptance to current/latest development.

\subsection{Theory on vicious circle of poverty}

This theory was first introduced by Nurkse (1953). This theory explains situation of poor families where the head of household $(\mathrm{HOH})$ is unable to provide the basic needs of the household such as food, clothing, shelter housing, education, health and many others (Bass, 2011). Poverty will continue to be inherited by future generations if the earlier $\mathrm{HOH}$ still unable to provide all the basic needs. Nurkse (1953) has detailed his theory through a source of income in developing countries that has not yet fully developed will cause the whole household suffered the same poverty problem. In a nutshell, this theory can be understood through Fig. 1.

According to Fig. 1, starting with demand, low income will cause low purchasing power among the poor as a result of an equally low productivity. Thus this chain will indirectly reduce their ability to save and invest. While on the supply side, low income will also result in low saving power capacity. This is because their income is only enough for their daily needs (Bass, 2011). This in turn, this will lead to lack of capital and low productivity. This cycle will eventually revert to lower revenue.

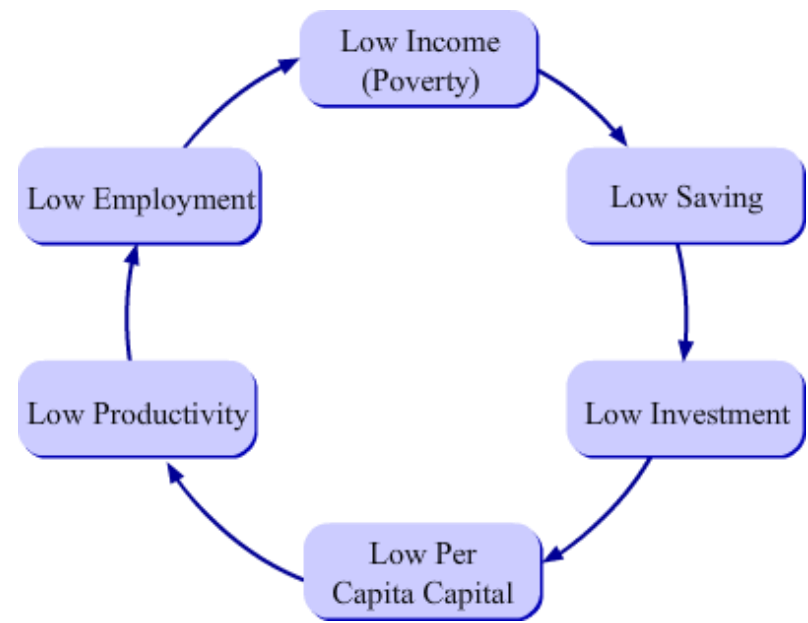

Fig. 1: Nurkse (1953) model of vicious circle of poverty

(VCP)

\subsection{Culture poverty theory}

Sharing the same poverty definition as Nurkse (1953), Lewis (1975) also looked at the issue of poverty as a serious phenomenon throughout the world. This theory was first developed by Lewis (1975). The results of his research found that poverty becomes culture among the poor that will remain despite being in a different place and time (Valencia, 1997). Lewis saw this poverty is not caused by economic factors, but has become a culture among the poor community.

He views that poverty was caused by adjustment of the poors to new living in a city. Thus, Lewis has identified cultural characteristics through his observation of the poor in his research of 4 stages. The stage begins with the society, community, family and individual (Valencia, 1997). Michael Harrington has developed the cultural values of the poor brought by Lewis through his study entitled 'The Other America: Poverty in the United States Harrington' (1962) also noted that the situation is known as the inherited poverty (Valencia, 1997).

\subsection{Social stratification theory}

If Nurkse see poverty was caused by economic factors and Lewis views it from culture and thought perspectives, Kinsley Davis in 1942 also sees poverty as a result of relative position and the different roles of both culture and thought in society. This means that the position of the poor is at the lowest level in the society structure (Valencia, 1997). The strata of society were once a very important aspect in society. For the elites, like kings and religious individuals are highly regarded, considered as important figures and respected by their society.

Apart from that, currently there are broader characteristics of the poor (Naschold, 2012; Barrett and Carter, 2013). Relatively poor is more visible 
everywhere. The previous structure of society regarded farmers, ranchers and others at the lower level before the level of slaves. Now the farmers, ranchers and others are more advanced along with the middle class community. Those who are perceived as poor are now homeless people, the group who make their own choices for their lives.

\section{Corporate social responsibility on education development}

A strong business organization is the one that makes good profit. Profit gains here not only refers to effectiveness of its leader, but also refers to benefits that they gain from the community. Therefore, it is an obligation for firms to contribute something to the community known as social service (Chapple and Moon, 2005; Abdifatah, 2013).

According to Maimunah and Abdul Rashid (2011), there are four corporate social responsibilities towards the Malaysian community, which are responsibility to the economy, law, ethics and philanthropy. Maimunah and Abdul Rasid has also devoted some analysis made by Secchi (2007) concerning theories involving CSR. Theories on CSR can be divided into 3 categories, namely 1) Utility theory, 2) Theory and Management 3) Relevancy Theory. Utility Theory explains that CSR exist as an ethic in corporate business. He also explained that community activities are an investment and this investment can also be profitable and returns back to the firm. If the Utility Theory is considered the community as an investment, Management Theory on the other hand views that the development and progress of a society is an indicator to economic performance of the firm (Chapple and Moon, 2005). Relevance Theory shows us the relationships that exist between the firm and its surroundings in terms of society and business, stakeholders, civil society and corporate social contract (Secchi, 2007; Vilanova et al., 2009; Abdifatah, 2013).

This study attempt to explore the meaning of poverty based on the NGO definition; identify the efforts created for the community and the impact from those efforts.

\section{Research methodology}

This study is carried out using case study. Creswell (2013) stated that the case study involves a lot of internal and external elements such as emotions, feelings, motivation, empathy and desire related to natural conditions of the individual. The purposive sampling method is used because it fulfils the criteria desired by the researchers. Data was collected through interviews, observations and document analysis and notes of reflection at workplace from May until July in 2015. For the record, one of the researchers is employee of the NGO. All information and data were recorded and analysed to build some codes manually based on the objectives and themes of the study. Since, each study must be conducted in good ethics, therefore, prior to interviews conducted, the respondents were notified earlier on confidentiality and approval for recorded interviews was requested.

\section{Findings and discussion}

CSR has its own implications when looking at the phenomena experienced by each function of society, particularly the structure of society that is interdependent and closely related in nature (Secchi, 2007). In the feudal era, education is not something that is very important as compared to interests of political, religious and economic. But now with the arising issues on politics and economy, it seems that education is now necessary as it deals with the society condition of living (Drucker, 1994; Hussein, 2012).

Based on the objectives of this study, the findings can be divided into three areas, namely, poverty, the efforts of NGOs and impact of NGO efforts.

\subsection{Poverty}

Poverty can be divided into two parts, namely absolute poverty and relative poverty. In brief, poverty refers to individuals who already have an income below the poverty line set by the government (Naschold, 2012; Barrett and Carter, 2013). Relatively poor refers to the middle class society that is undoubtedly poorer than the higher society group. However, given the economic situation nowadays, individuals who used to be in the middle class can also be almost equal to the lower society group.

Thus, classification of the poor seems to lose its relevance compared to poverty phenomenon nowadays. A new meaning for the poor can be divided into two parts, the economic poverty and mindset poverty (Valencia, 1997). Interview with the respondent found that:

"Definition of poverty is actually based on a number of factors, which are both economically and in terms of the mindset. In economic terms those who have an income that is scarce compared to others while my mindset poverty is a new expression for the target groups of the poor is mainly in terms of behaviour, attitude and so on"

Economic poverty still refers to the amount of income while mindset poverty refers to the behaviour, attitudes etc. Mindset poverty is a new term that exists nowadays for the poor group. Mindset poverty as observed can affect anyone even though their economic situation is at the satisfactory level because it grows from the inner self of the individual and affects other generation.

How does mindset poverty takes place? Mindset poverty can be associated with Culturally Poor Theory stated by Lewis that poverty is not due to economic factors, but has become a culture among the poors. Some of the obvious characteristics are they often keep away from society, lack of participation and lack of integration in society. This was stated by the respondent through his 
observation of the organization adopted children namely:

"Ok, from our observation poor students have low self-confidence. They are too embarrassed to go forward, too shy to express their views, too shy to interact. This we can see, yes, I can see this during our Adoption Foundation program when we take care of foster children of more than one hundred and fifty kids and this is the picture that we can see when we gathered in specific programs that bring them together. Although they have joined this program for three years, for example, some four years but they still do not know each other."

According to the respondent, their (foster children) were included in the program for some time but they still have the self-distant attitude meaning they are not eager enough to get to know other people in the same program. When asked whether they know each other they seem a bit shy to interact. This is in contrast to students who live in cities where they have higher self-confidence level:

"He's different with students in urban areas if they went to summer camp or anywhere else, one hour is enough for them."

With regard to education dropout issue, respondents indicated that the dropout problem should not happen in Malaysia as the government always ensure that education is accessible to all citizens who are eligible. The government also provides many schools across the country, even for poor students they are exempted from paying tuition fee and provided with Poor Students Trust Fund (PSTF), supplementary food program and many more. Poverty stems from mentality of their parents who are not concerned with education and do not carry out their responsibilities.

"For me not because our country wherever the poors live the government will always help no matter they live in rural areas, in urban, rural and so on because for poor children as they are excluded from paying tuition fee and so on, have also given what is called food supplement for poor students in the school and there is also money (inadvertently) pocket given to them, and KWAM program."

The government does not focus only on rural students but also to those in remote areas of the indigenous peoples. Definitely it is quite difficult if there are children in the neighbourhood at school ages who face difficulty to go to school. Accordingly, the Department of Orang Asli (JAKOA) took the initiative to hire a van for transportation to ensure that these children do not fall behind in their studies. According to the respondent on his recent visit of an indigenous village in Kampung Bawong, Sungai Siput found that the government also provides dormitories as residential place for Aboriginal children so that they can give full attention to their studies.

"Ok. The situation is somewhat isolated case for me but nevertheless the efforts of what has been done for me by the state government to address the problems of those in rural areas. So such isolated cases are mostly likely to happen to me in Sabah and
Sarawak but I don't think this happen in the peninsular areas. But for example in villages of indigenous people own even though it's far, hilly and so on, but the government has always helped for example JAKOA. I know they help to pay transportation money for the van to send students to school every month. They pay for every month to make sure the kids were going to school. And if we see for example in some areas in Ulu Kinta for example, then recently I visited this village in Perkampungan Bawong in Sungai Siput the government actually provide hostels for the aboriginal students people so the kids can totally focus on learning."

Mindset poverty does not stem from major issue and also involves many individuals rhythm but it occurs as a result of circumstances over time. It is about behavior, thoughts and attitudes of an individual in trying to change towards a better life. Respondents felt that if an individual still remains in negative mentality, the desire to succeed will always be at a low level. They will remain trapped in poverty.

"Ok, this mentality exists as a result of the current situation yes current situation. But the current situation, we have to remember our lives no-one can change the fate ourselves unless we ourselves want to change. Ok, so if they still keep such mentality which is negative and so surely their hope to changes, to be successful is extremely at low levels compared with those who have middle class standard"

Should this happen, the values of this culture will finally be passed down to the next generations. Therefore, the parents or the older generation like their forefathers, they should be strong, firm in fighting the diseases of poverty. Poverty trap as stated by Nurkse (1953) should no longer be relevant nowadays. If this continues then poverty is not the impact of being poor, but being poor is the cause for poverty. To be exact, being poor is the root cause for poverty (Naschold, 2012).

\subsection{The efforts of the non-governmental organizations}

Government has played a role to overcome poverty, not only economically, but also through education that is seen as the starting point that cause poverty if it is not curbed (Hargreaves and Shirley, 2009). However, these efforts will not run smoothly if all the responsibilities are shouldered only by one party (Amran and Devi, 2008). Therefore, the existence of non-governmental organizations to some extent will be able to assist the government through CSR. A firm is not only for profit alone but they also carry out social responsibility as giving back to the community in the name of social service.

Over the past five years of establishment of the organization, the organization is responsible in the first run of the adopted children programme held by the organization. Those chosen were more than 150 students who came from poor families with 
academic potentials. Thus, the welfare of their education are monitored and recorded from year to year to ensure that they will not be left behind in education despite living in deprivation. The organization has been giving pocket money to them on a monthly basis and provides them with school necessaries at the end of each school year under 'Back To School' program. However, improvements have been made over the years; the organization does not focus only on the adoption of children but has also developed the program to almost all students in Perak state. With the help of local officials, the State Education Department, schools, village chiefs, headmen and individuals, now the number of recipients has reached almost thousands of poor students.

According to the respondent, characters of the students also are quite different than those who come from middle class families. For adopted children in the organization, it was observed that they lack of self-esteem and being aloof at most times.

"So this is how we can describe that low he has what self-confidence, he had an interaction with friends and so on. Because they are a bit afraid. Scared, shy and so on and keep to themselves during the program."

In addition to providing their welfare needs, the organization also runs programs in the form of motivation, study tour, camp centre visit and so forth to encourage their will to succeed and increase selfconfidence. Last but not least, motivational programs are also targeted to selected students in each district.

Every programme is not shouldered to the organizations alone but they are implemented in collaboration with other agents of change in the name of corporate social responsibility. Example given by the respondents is a program which was carried out since two years ago is collaboration with Maybank. Maybank has sponsored nearly 200 poor students for tuition on weekly basis. The selection of students is based on students who will be sitting Sijil Pelajaran Malaysia (SPM) exam this year. Two critical subjects chosen for the tuition class are English and Mathematics.

"Ok, we always collaborate with other organizations such as our recent collaboration is with the banks. So Maybank sponsored nearly 200 poor students to what attend weekly tuition at several schools."

The organization also collaborated with another organization in Perak, namely K-Silver Incorporated to conduct a number of seminars to expose students on the importance of information technology. The program, known as Knowledge Application, New Media, Communication and Technology, Integrated Learning or in its abbreviations KANCIL are programs that emphasize education for the 21st century that is competitive in line with advances of information technology nowadays. Throughout the program, in addition to new knowledge, students can also enjoy the fun and educational atmosphere. Indirectly, this program can motivate students.
"In addition, we also collaborate with other government agencies such as KPerak where we make the seminar, a number of seminars to expose rural students about the importance of IT and business and we will strive for this from time to time."

Following the interviews, the respondent also shared information on social responsibility program that will be held by the organization in collaboration with Maybank Foundation RISE program for next year. According to the respondent, RISE is a program to help build the capacity of people with disabilities (PWDs) in each district in the state of Perak.

"We are in discussions with several other agencies or corporations to work together with us for us what is trying to change the mindset of this poor community in Perak. Ok, then the most immediate example in January we will be together with the one that is provided by Maybank Foundation under a program called RISE (respondents mentioned RISE), which we will create in every district for example to help disabled persons with disabilities in every area for their business. For example, in business and have more income than what they earn now. So we already have collaboration with a company for us to tackle the disabled groups."

Although the program is not directly in the field of education, this program can change the mindset of the poor families especially those who are having family member with disabilities. To remove a person from the poverty trap, it should be targeted not only to children but also to their parents to ensure that their children will get a better life in the future.

\subsection{Impact from NGO efforts}

Every problem that is faced with determination and effort is definitely going to pay off. It depends on whether these efforts give positive and negative impact (Nisar, 2013). For positive effect, the improvement and enhancement efforts must be intensified. Otherwise, the efforts undertaken must be put under close review and improved to ensure they are not wasted and become meaningless.

Throughout the organization initiatives to help the destitute students, their effort begins to show success. According to the respondent, there are some individuals who were once sent for seminars, tuition etc. and has continued their studies at university level. It is a great success for the organization even if not as a whole but the efforts have started to show positive outcome.

Speaking of the poverty trap and vicious circle of poverty, during the respondent's visit and participation in the program he found that a number of children now have also successfully stepped out from the poverty trap. Under the program known as Travel Syawal held recently in conjunction with Aidilfitri celebration, the organization paid a visit and conducted census to the target groups. For example there is one poor family but the son has managed to become an engineer in a well-known 
company i.e. Petronas. Seeing such situation certainly brings joy and pride to the organization.

"Yes, in fact we are the ones who watched from time to time when we went down to the field. Indeed, among poor children there is actually successful and actually become outside of what we imagine. Some became engineer with Petronas and others so thank to Allah. But this happened to me can only happen if the attitude and mentality of the parents are positive."

With reference to the tuition program held by the organization in collaboration with Maybank has yet to show results because they are still waiting for their exam results. However, the organization will not ignore the students in case their results turn out to be unsatisfactory. The organization is prepared to help them in other skills courses such as courses in Giat Mara, Community College and many others.

"We've guard their data with us so this example should they fail at Form Five secondary level, we still do this to help. For example we will put them to places what to get service skills such as Giat Mara and so on, so this is also one of the business we are the ones to ensure they have a better future."

Meanwhile, the students' performance will still be put under supervision and recorded in terms of their attendance and excellence to ensure they are not overlooked or left out during the tuition session carried out. The organization eventually would like to see them achieve success in the end.

Every human being wants to achieve success. Remembering the days of school a long time ago, when asked about ambition, almost all of us would aspire to become teachers, doctors, engineers, lawyers and the list goes on. No one wants to work as farmers, labourers, general workers who are regarded as lower class work. Nowadays all trying to earn a good living, and as far as possible do not want to work in lower occupational groups. When asked about the impact on the structure of society to the respondent, he has his own view.

According to the respondent, the margin of the economy wealth for each country is different. The revenue obtained for lower class groups are also very different. There may be some countries that pay their lower class workers thousands of dollars, while for some countries they only receive hundreds of dollars. In addition, most tasks in the developed countries such as laundry and cleaning services, general services have been implemented through robotics. Accordingly, high education still does not made any changes to the structure of society.

\section{Suggestions and conclusions}

Education is an early start for a person to get a better life. CSR does not harm or benefit any party but it brings a win-win situation (Vilanova et al., 2009). The attitude for social responsibility is also supposed to be carried out in team and mutual assistance in each individual since childhood. Education is a mechanism to get out of poverty (Hargreaves and Shirley, 2012; Hussein, 2012).
Definitely great effort is required but it will eventually pay off. Following all the efforts carried out in this study, it can be suggested to nongovernmental organizations to implement programs of assistance in the form of education in which all materials and goods to be supplied in a box. Therefore, apart from running the program motivation, educational aid box can also be given as a gift to the students. Contents of which can be filled into the box is in the form of stationery, motivational books, reference books, notebooks etc.

Apart from running programs to students, motivation program should also be carried out to the parents so that they understand the importance of education to help their families out of the poverty trap. The non-governmental organizations can also work with the Ministry of Education to encourage learning outside the classroom (Secchi, 2007). The learning environment in the classroom for a long period of time may sometime cause boredom to the students.

It is also proposed for future research that respondents must come through a variety of parties. For the efforts that have been carried out, the study needs review on their outcome and impact on nongovernmental organizations, schools, students, parents and the community. Researchers need to see the efforts that are undertaken to assist the school in governance, ease the burden on parents, improve student performance and bring prosperity in society. Observation should be done consistently on behavior and attitudes of students and parents before and after the programs held by non-governmental organizations. Data, performance records and their presence can also be monitored to see the success of the programs. Not only educational achievement, school and home environment also play important role in identifying deficiencies and constraints faced by students.

Numerous suggestions were proposed for improvement of education in the country, both to the researchers and agents of social change (Amran and Devi, 2008; Nisar, 2013). Even so, every plan should be carried out with good framework to ensure that they are implemented successfully. However, as long as self-intention is pure, all the effort will undoubtedly receive good blessings and all things will run smoothly. Social responsibilities is not something meaningless, in fact it is something noble and highly respected and give long-lasting impact on community and nation (Chapple and Moon, 2005; Abdifatah, 2013).

\section{References}

Abdifatah AH (2013). Corporate social responsibility disclosures over time: evidence from Malaysia. Managerial Auditing Journal, 28(7): 647-676.

Amir HD (2009). Sekolah dan masyarakat. Quantum Books, Tanjong Malim, Malaysia.

Amran A and Devi SS (2008). The impact of government and foreign affiliate influence on 
corporate social reporting: The case of Malaysia. Managerial Auditing Journal, 23(4): 386-404.

Barrett CB and Carter MR (2013). The economics of poverty traps and persistent poverty: empirical and policy implications. The Journal of Development Studies, 49(7): 976-990.

Bass H (2011). Ragner Nurske's development theory: Influences and perceptions. In: Kattel R, Kregel J and Reinert E (Eds.), Classical Development Economics and its Relevance for Today, Anthem Press, London: 183-202.

Chapple W and Moon J (2005). Corporate social responsibility (CSR) in Asia a seven-country study of CSR web site reporting. Business and Society, 44(4): 415-441.

Creswell JW (2013). Qualitative inquiry and research design: Choosing among five approaches. $3^{\text {rd }}$ Edition, Sage Publications, Thousand Oaks, USA.

Drucker P (1994). Post-capitalist society. Routledge, London, UK.

Hargreaves A and Shirley D (2009). The fourth way: The inspiring future for educational change. Corwin Press, Thousand Oaks, USA.

Hargreaves A and Shirley D (2012). The global fourth way. Corwin Press, California, USA.

Hussein A (2012). Mission of public education in Malaysia: The challenge of transformation. University of Malaya Press, Kuala Lumpur, Malaysia.
Lewis $O$ (1975). Five families: Mexican case studies in the culture of poverty. Basic Books, New York, USA.

Maimunah I and Abdul Rashid J (2011). Pendidikan dan masyarakat: Peranan institusi sosial. Penerbit Universiti Putera Malaysia, Serdang, Malaysia.

Mustaruddin S, Norhayah Z and Rusnah M (2010). Corporate social responsibility disclosure and its relation on institutional ownership: Evidence from public listed companies in Malaysia. Managerial Auditing Journal, 25(6): 591-613.

Naschold F (2012). "The poor stay poor": Household asset poverty traps in rural semi-arid India. World Development, 40(10): 2033-2043.

Nisar A (2013). Educational poverty by design: A case of mismanagement of national resources. World Journal of Education, 3(5): 34-44.

Nurkse R (1953). Problems of Capital Formation in Underdeveloped Countries. Oxford Univ. Press, New York, USA.

Secchi D (2007). Utilitarian, managerial and relational theories of corporate social responsibility. International Journal of Management Reviews, 9(4): 347-373.

Valencia R (1997). The evolution of deficit thinking: Educational thought and practice. Falmer, London, UK.

Vilanova M, Lozano JM and Arenas D (2009). Exploring the nature of the relationship between CSR and competitiveness. Journal of Business Ethics, 87(1): 57-69. 